\title{
Friction and heat transfer for inclined surfaces in relative motion to an air stream under buoyancy effect
}

\author{
J.A. Souza ${ }^{a, *}$ J.V.C. Vargas ${ }^{a}$, M.V.A. Bianchi ${ }^{b}$ \\ a Programa de Pós-Graduação em Engenharia de Materiais e Processos, PIPE, Departamento de Engenharia Mecânica, \\ Universidade Federal do Paraná, CP 19011, Curitiba, PR 81531-990, Brazil \\ ${ }^{\mathrm{b}}$ Departamento de Engenharia Mecânica, Universidade Federal do Rio Grande do Sul, CP 17819, Porto Alegre, RS 90035-972, Brazil
}

Received 10 October 2002; accepted 26 April 2003

\begin{abstract}
Heat transfer from a surface in motion relative to either a stationary or moving fluid occurs in many materials processing applications such as hot rolling, extrusion, drawing, and drying. In this study, an analysis has been carried out to predict the convective transport occurring between air and a continuous inclined surface which moves with an assisting or opposing flow with respect to the free stream in the presence of gravity. The steady flow of air is assumed laminar and is modeled by using a two dimensional (2-D) complete set of conservation equations, subject to the appropriate boundary conditions. The equations were solved numerically by employing the finite element method. Predictions for the local dimensionless skin friction and heat transfer are made for different configurations of the relative position of the surface and the free stream. The numerical results of the present study for the buoyancy-assisting and opposing flows on vertical surfaces are validated by direct comparison with the available published data. New results are presented for inclined surfaces with the buoyancy-assisting and opposing flows. The buoyancy-assisting results are then correlated for wide ranges of inclination angles and moving sheet relative velocities.
\end{abstract}

(C) 2003 Elsevier Inc. All rights reserved.

Keywords: Moving sheets; Laminar regime; Finite element method

\section{Introduction}

Heat transfer from a surface in motion relative to either a stationary or moving fluid occurs in many materials processing applications, such as hot rolling, extrusion, drawing (Jaluria, 1992; Viskanta, 1992), and paper drying (Lindsay, 1992; Calkin and Parsons, 1957). Examples of processes include continuous casting, plastic forming, bonding, annealing and tempering, heat treatment and many others. Most of the literature on this problem has focused on laminar flow for a surface moving through a stagnant fluid. Sakiadis (1961a) was the first to analyze boundary layer flow and heat transfer on a continuous moving surface. Both approximate and exact solutions for the momentum equation were obtained for laminar flows on a surface \footnotetext{
3129 .

${ }^{*}$ Corresponding author. Tel.: +55-41-361-3307; fax: +55-41-361-

E-mail address: jvargas@demec.ufpr.br (J.A. Souza).
}

moving through a stagnant fluid (Sakiadis, 1961a,b,c), and numerous references on the subject are cited elsewhere (Lindsay, 1992; Calkin and Parsons, 1957; Erickson et al., 1966; Tsou et al., 1967).

The first analysis treating simultaneous motion of both the fluid and the surface was published by Klemp and Acrivos (1972). They studied the flow when the free stream is parallel but in the opposite direction to the moving plate, using a similarity method. A critical value of the moving surface velocity to the free stream velocity ratio was found to be of 0.3541 .

The inability to obtain similarity solutions for higher values of this ratio was attributed to boundary layer separation from the moving plate, and the mathematical reasons for this limit were discussed by Hussaini and Lakin (1987). Forced convection heat transfer occurring in this flow situation was studied by a number of researchers (Gampert and Abdelhafez, 1979; Abdelhafez, 1985; Chapiddi and Gunnerson, 1989). Mixed convection on a stationary horizontal plate was also considered 
(Ramachandran et al., 1983), and the set of nonsimilar equations was solved by using the finite difference and the local nonsimilarity methods.

Forced convection from an isothermal horizontal plate moving in a parallel counter flowing fluid stream was analyzed by Bianchi and Viskanta (1993). Similarity and integral methods of solution were used to solve the set of boundary layer equations, but no solutions could be obtained for velocity ratios greater than 0.3542 , using the similarity method.

Ramachandran et al. (1987a) studied the flow and heat transfer from vertical and inclined moving sheets with the presence of buoyancy-assisting effects, under the boundary layer assumptions. However, they studied only the cases where the sheet moves in the same direction as the free stream, and they neglected the streamwise pressure gradient in their formulation, excluding, for example, the horizontal plate configuration. In many practical situations, such as continuous casting (Minkoff, 1992), motion of a horizontal surface can exist in the presence of a free stream flow of a fluid. The heat transfer rate in this situation is of importance if the temperature has to be controlled. Another study by Ramachandran et al. (1987b) develops the correlations for inclined moving sheets in mixed convection either with uniform surface heat flux or with uniform surface temperature, although they are not valid for all inclination angles. $x, y \quad$ Cartesian coordinates, $\mathrm{m}$

$X, Y$ dimensionless Cartesian coordinates

\section{Greeks}

$\alpha \quad$ angle of the plate with the horizontal

$\alpha_{\mathrm{T}} \quad$ thermal diffusivity, $\mathrm{m}^{2} \mathrm{~s}^{-1}$

$\beta \quad$ coefficient of volumetric thermal expansion, $\mathrm{K}^{-1}$

$\lambda \quad$ moving sheet to free stream velocity ratio

$v \quad$ kinematic viscosity, $\mathrm{m}^{2} \mathrm{~s}^{-1}$

$\mu \quad$ dynamic viscosity, $\mathrm{kg} \mathrm{m}^{-1} \mathrm{~s}^{-1}$

$\xi \quad$ Richardson number, Eq. (8)

$\theta$ dimensionless temperature

$\rho$ density, $\mathrm{kg} \mathrm{m}^{-3}$

$\tau \quad$ shear stress, $\mathrm{N} \mathrm{m}^{-2}$

Subscripts

L surface trailing edge

$x, y \quad$ vector components at $x$ - and $y$-directions

$\mathrm{w} \quad$ wall

$\infty \quad$ free stream

Superscript

$\overline{(\cdot)} \quad$ wall averaged quantity
Chen (2000a) performed an analysis of thermal transport, occurring in the boundary layer of a horizontal nonisothermal moving sheet in forced convection, with the surface temperature assumed to have a power law variation. Pop et al. (1995) developed a series solution for an inclined moving sheet in natural convection, with a small angle of inclination to the horizontal.

Ali and Al-Yousef (1998) studied the boundary layer flow over a uniformly moving vertical surface with suction or injection, obtaining similarity solutions subject to power law temperature and velocity boundary conditions. The effect of various governing parameters is investigated, such as the Prandtl number and the power law exponent. Chen (2000b) presented a numerical study of the flow and heat transfer characteristics associated with a heated, continuously stretching surface being cooled by a mixed convection flow. A power law surface velocity was assumed for the continuously stretching sheet, and two conditions of surface heating, i.e., power law temperature and heat flux. Nonsimilarity solutions were obtained for the local Nusselt number and friction coefficient, investigating the effect of surface velocity and buoyancy force.

More recently, Ali and Al-Yousef (2002) considered in their work both the buoyancy-assisting and opposing flows and solved the moving surface problem obtaining similarity and local similarity solutions. They studied 
the effects of a mixed convection boundary layer adjacent to a continuous moving upward vertical surface, with suction or injection. It was assumed that both the temperature and the moving surface velocity varied according to a power law. The effect of the Prandtl number, injection parameter and buoyancy parameter were investigated. Critical values were found and a closed form analytical solution was presented as a special case of the energy equation.

Ali (1995) and Chen (1999) studied the horizontal moving sheet with suction or injection with no buoyancy effects. The flow and heat transfer characteristics of both the arrangements were evaluated under the boundary layer assumptions, for a similarity solution method. AlSanea and Ali (2000) presented heat and fluid flow solutions for a horizontal moving sheet with suction or injection, studying the effect of the extrusion slit. Their work has been the only one found in the literature that utilizes the conservation equations in their complete form to analyze the heat and fluid flow, moving sheet problem. The finite volume method (Patankar, 1980) was utilized to obtain the numerical results for the nonsimilar and similar regions, assuming a uniform temperature profile on the moving sheet.

A review of the literature shows that the heat and fluid flow solutions that cover all the buoyancy-assisting and opposing flows for mixed convection on inclined surfaces are not available. Therefore, the objectives of the present work are: (i) to predict fluid friction and heat transfer characteristics along inclined surfaces in laminar flow both for buoyancy-assisting and opposing flows with a two dimensional complete set of conservation equations and (ii) to correlate the bulk of the numerical results in the form of analytical expressions valid for wide ranges of inclination angles and moving sheet relative velocities.

\section{Mathematical model}

Consider a solid inclined flat surface (sheet) of temperature $T_{\mathrm{w}}$ issuing from a slot at a constant velocity $u_{\mathrm{w}}$ and being rolled on a cylinder. Four different flow configurations may be encountered depending on the inclination of the plate (buoyancy-assisting or opposing flow) and the ratio of the plate velocity to the free stream velocity (positive or negative), as shown in Fig. 1. A buoyancy induced flow could either assist or oppose the forced flow in the free stream, but only the cases of aiding flow can be considered appropriately under the boundary layer assumptions. The opposing flow situations (i.e., $\alpha<0$ in Fig. 1) should be treated with a complete set of conservation equations, i.e., without the boundary layer approximations.

A Cartesian coordinates system $(x, y)$ is fixed on the moving sheet either at the slot or at the rolling cylinder.

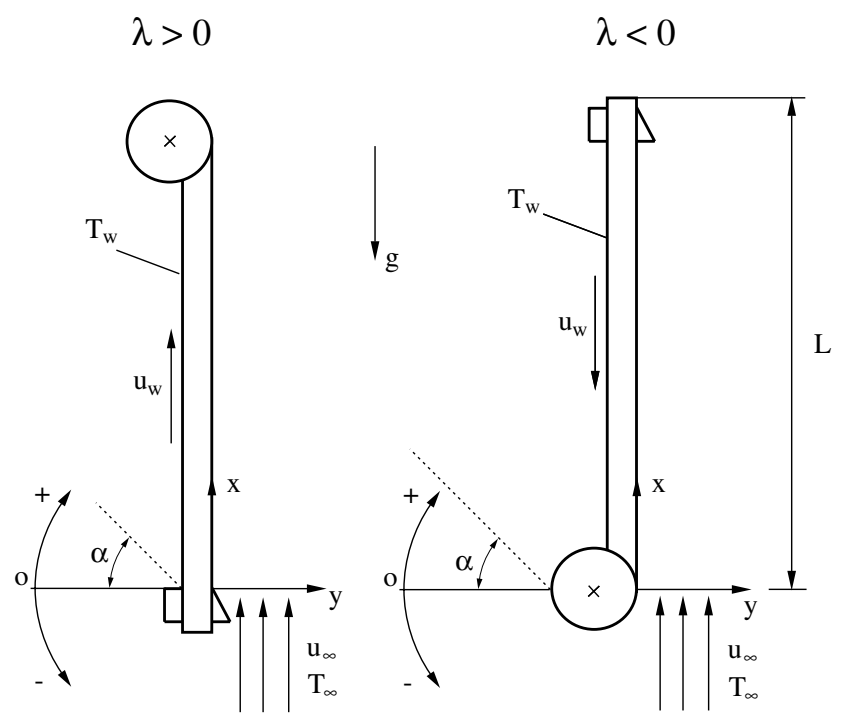

Fig. 1. Problem sketch.

The gravity acceleration vector is fixed in the vertical direction pointing downwards. The moving sheet inclination with respect to the horizontal is defined by an angle $\alpha$ which is in the range from $-90^{\circ}$ to $90^{\circ}$, as shown in Fig. 1. This way, all possible configurations with the forced flow over the plate are covered by the analysis. The dimensionless parameter $\lambda$ is the ratio between the moving sheet velocity, $u_{\mathrm{w}}$, and the free stream velocity, $u_{\infty}$, i.e.

$\lambda=\frac{u_{\mathrm{w}}}{u_{\infty}}$

To characterize most materials processing applications, it is assumed that the moving sheet is at a uniform temperature, higher than ambient temperature, i.e., $T_{\mathrm{w}}>T_{\infty}$. Therefore, four different flow configurations are described by Fig. 1.

(a) The air stream and sheet velocities have the same sign

1. $\lambda>0$ and $\alpha>0$ : buoyancy-assisting flow;

2. $\lambda>0$ and $\alpha<0$ : buoyancy-opposing flow.

(b) The air stream and sheet velocities have opposite signs

3. $\lambda<0$ and $\alpha>0$ : buoyancy-assisting flow;

4. $\lambda<0$ and $\alpha<0$ : buoyancy-opposing flow.

The present treatment utilizes the two dimensional complete set of conservation equations to formulate the problem, although a simplified set of equations under boundary layer assumptions may be used for buoyancyassisting flows, as discussed earlier in the text (Ramachandran et al., 1987a). However, the complete set of conservation equations is required to obtain appropriate results for buoyancy-opposing flows. Under the assumptions of laminar, constant property flow with 
negligible viscous dissipation and Boussinesq approximation, the dimensionless conservation equations, for $-90^{\circ} \leqslant \alpha \leqslant 90^{\circ}$, are written as

$\frac{\partial U}{\partial X}+\frac{\partial V}{\partial Y}=0$

$U \frac{\partial V}{\partial X}+V \frac{\partial V}{\partial Y}=-\frac{\partial P}{\partial Y}+\frac{1}{R e_{\mathrm{L}}}\left(\frac{\partial^{2} V}{\partial X^{2}}+\frac{\partial^{2} V}{\partial Y^{2}}\right)$

$$
-\sin (\alpha) \xi_{\mathrm{L}} \theta
$$

$U \frac{\partial U}{\partial X}+V \frac{\partial U}{\partial Y}=-\frac{\partial P}{\partial X}+\frac{1}{R e_{\mathrm{L}}}\left(\frac{\partial^{2} U}{\partial X^{2}}+\frac{\partial^{2} U}{\partial Y^{2}}\right)$

$$
-\cos (\alpha) \xi_{\mathrm{L}} \theta
$$

$U \frac{\partial \theta}{\partial X}+V \frac{\partial \theta}{\partial Y}=\frac{1}{P e_{\mathrm{L}}}\left(\frac{\partial^{2} \theta}{\partial X^{2}}+\frac{\partial^{2} \theta}{\partial Y^{2}}\right)$

where the dimensionless variables are defined as

$(X, Y)=\frac{(x, y)}{L}, \quad(U, V)=\frac{(u, v)}{u_{\infty}}$

$\theta=\frac{T-T_{\infty}}{T_{\mathrm{w}}-T_{\infty}}, \quad P=\frac{p-\rho\left(g_{x} x+g_{y} y\right)}{\rho u_{\infty}^{2}}$

where $L$ is the length of the exposed part of the moving sheet, $R e_{\mathrm{L}}=u_{\infty} L / v$ and $P e_{\mathrm{L}}=u_{\infty} L / \alpha_{\mathrm{T}}$ are the Reynolds and Peclet numbers based on $L$, respectively, and $g_{x}=-|g| \sin (\alpha)$ and $g_{y}=-|g| \cos (\alpha)$ are the components of the gravity acceleration vector, $g$.

The relative influence between the forced and natural convection effects is described by the ratio

$\xi_{\mathrm{L}}=\frac{\left|g \beta\left(T_{\mathrm{w}}-T_{\infty}\right) L^{3} / v^{2}\right|}{\left(u_{\infty} L / v\right)^{2}}=\frac{\left|G r_{\mathrm{L}}\right|}{\operatorname{Re}_{\mathrm{L}}^{2}}$

where $G r_{\mathrm{L}}$ is the Grashoff number based on $L, \xi_{\mathrm{L}}$ is also known as the Richardson number based on $L$.

In Eq. (3), when $\alpha>0, \sin (\alpha)>0$, therefore the buoyancy term is negative, i.e., the gravity component in the $x$-direction is negative, determining a buoyancyassisting flow to the free stream. On the other hand, when $\alpha<0, \sin (\alpha)<0$, therefore the buoyancy term is positive, i.e., the gravity component in the $x$-direction is positive, determining a buoyancy-opposing flow to the free stream. In Eq. (4), for $-90^{\circ} \leqslant \alpha \leqslant 90^{\circ}, \cos (\alpha)>0$, therefore the buoyancy term is negative, i.e., the gravity component in the $y$-direction is always negative.

To complete the mathematical formulation, Fig. 2 shows the computational domain and the appropriate boundary conditions for the problem, as follows:
(A) $U=1, \quad V=0, \quad \theta=1$
(B) $U=\lambda, \quad V=0, \quad \theta=1$
(C) $\frac{\partial U}{\partial y}=\frac{\partial \theta}{\partial y}=0, \quad V=0$

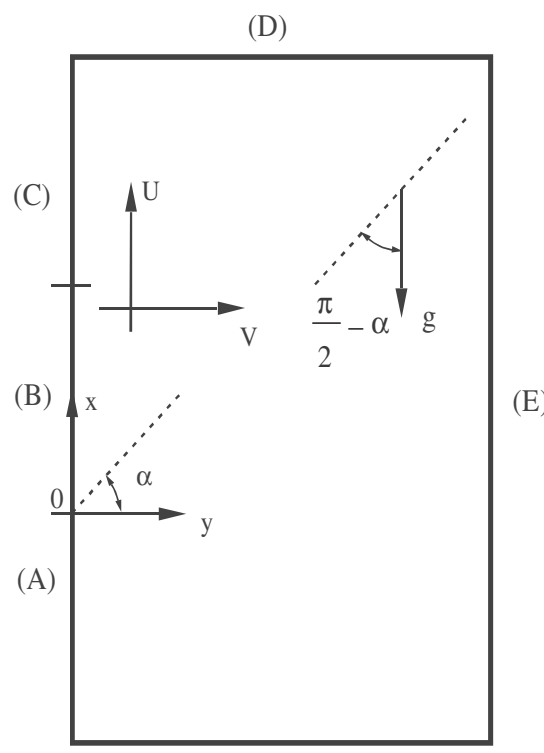

(A)

Fig. 2. Computational domain.

(D) $\frac{\partial U}{\partial X}=\frac{\partial V}{\partial X}=\frac{\partial \theta}{\partial X}=0$

(E) $\frac{\partial U}{\partial Y}=\frac{\partial V}{\partial Y}=\frac{\partial \theta}{\partial Y}=0$

The problem consists of solving Eqs. (2)-(5), to determine the velocity and temperature fields in the computational domain subject to boundary conditions, as defined in Fig. 2. Then, the local skin friction coefficient and the local Nusselt number are computed for a general location at the surface, $x$, according to their definitions, as follows:

$$
\begin{gathered}
C_{\mathrm{f}, x}=\frac{\tau_{\mathrm{w}}}{\frac{1}{2} \rho u_{\infty}^{2}}=\frac{\mu\left[\frac{\partial u(x)}{\partial y}\right]_{y=0}}{\frac{1}{2} \rho u_{\infty}^{2}}=2\left[\frac{\partial U(X)}{\partial Y}\right]_{Y=0} R e_{\mathrm{L}}^{-1} \\
N u_{x}=\frac{h x}{k}=\frac{-k\left[\frac{\partial T(x)}{\partial y}\right]_{y=0}}{\left(T_{\mathrm{w}}-T_{\infty}\right)} \frac{x}{k}=-X\left[\frac{\partial \theta(X)}{\partial Y}\right]_{Y=0}
\end{gathered}
$$

The wall averaged skin friction coefficient is calculated by first obtaining the wall averaged shear stress, $\bar{\tau}_{\mathrm{w}}$, such that $\bar{C}_{\mathrm{f}}=\bar{\tau}_{\mathrm{w}} /(1 / 2) \rho u_{\infty}$. The final result is given by

$\frac{1}{2} \bar{C}_{\mathrm{f}} R e_{\mathrm{L}}^{1 / 2}=\int_{0}^{1}\left[\frac{\partial U(X)}{\partial Y}\right]_{Y=0} \mathrm{~d} X R e_{\mathrm{L}}^{-1 / 2}$

Similarly, the wall averaged Nusselt number is calculated by first obtaining the wall averaged convective heat transfer coefficient, $\bar{h}$, such that $\overline{N u}=\bar{h} L / k$. The final result is given by

$\overline{N u} R e_{\mathrm{L}}^{-1 / 2}=-\int_{0}^{1}\left[\frac{\partial \theta(X)}{\partial Y}\right]_{Y=0} \mathrm{~d} X \operatorname{Re}_{\mathrm{L}}^{-1 / 2}$ 


\section{Results and discussion}

For the problem considered in this paper, the model described in Section 2 allows the numerical computation of the local skin friction coefficient, $C_{\mathrm{f}, \mathrm{L}}$ and the local Nusselt number at the surface trailing edge, $x=L$, that are defined by Eqs. (14) and (15), respectively, which were used to validate the present numerical results by direct comparison with previously published numerical results in the literature. On the other hand, to present new results for inclined surfaces either with buoyancyassisting or opposing flow to the free stream, the wall averaged skin friction coefficient and Nusselt number, as defined in Eqs. (16) and (17), were utilized rather than the local quantities. Numerical solutions were obtained for air $(\operatorname{Pr}=0.72), \quad 1 \leqslant R e_{\mathrm{L}} \leqslant 1000, \quad-90^{\circ} \leqslant \alpha \leqslant 90^{\circ}$, $-0.3 \leqslant \lambda \leqslant 0.3$ and $0 \leqslant \xi_{\mathrm{L}} \leqslant 100$ (i.e., from forced, mixed to natural convection conditions).

The finite element method was applied to solve the two-dimensional problem. Fluid flow and heat transfer 2-D, isoparametric, 4-noded linear elements were written to be used as subroutines for the finite element analysis program (FEAP), which was originally developed for solid mechanics problems by Zienkiewicz and Taylor (1989). The fluid flow and the heat transfer variational and discrete equations were implemented as described by Reddy and Gartling (1994) for the coding of elements, including either a Galerkin or an upwinding scheme. A mesh with a total of 1170 nodes and 1102 elements, distributed in $30 \times 39$ nodes and $29 \times 38$ elements, was selected for the computational domain of Fig. 2, more refined in the vicinity of the plate and coarser in the direction of the free stream, such that the Euclidean norm of the solution did not change, in comparison with more refined meshes.
Initially, for the vertical wall configuration $\left(\alpha=-90^{\circ}\right.$ or $\alpha=90^{\circ}$ ), the numerical results obtained with the present model were validated by direct comparison with available published data. Although the results were validated for several plate speeds and Reynolds numbers, for the sake of conciseness, only the results for the case where the plate is moving in the opposite direction to the free stream $(\lambda=-0.3)$ are presented to illustrate the validation procedure of the local skin friction coefficient against the results of Bianchi et al. (1997), since Ramachandran et al. (1987a) did not present results for the local skin friction coefficient. To validate the local Nusselt number results, a comparison is presented with the results obtained by Ramachandran et al. (1987a). The comparison is shown only for the cases where the plate is moving in the same direction as the free stream (for brevity, only for $\lambda=0,0.5$ ), since Ramachandran et al. (1987a) did not treat cases where the plate is moving in the direction opposite to the free stream in their work. For the aiding flow configuration, a high Reynolds number $\left(R e_{\mathrm{L}}=1000\right)$ was selected as shown in Figs. 3 and 4, and for the opposing flow configuration, results for $R e_{\mathrm{L}}=1$ are shown in Fig. 5. First, the results for the aiding flow configuration are addressed, i.e., $\alpha=90^{\circ}$. In Fig. 3, regarding the comparison with previously published data obtained with a complete finite element formulation by Bianchi et al. (1997), the results practically match. Fig. 3 also shows a good qualitative agreement with results obtained with a boundary layer formulation by Bianchi et al. (1997). As it is seen in Fig. 4 , the comparison between the present results and the previously published results obtained with a boundary layer formulation (Ramachandran et al., 1987a) shows that there is a good qualitative agreement between them. The slight quantitative differences may be explained by

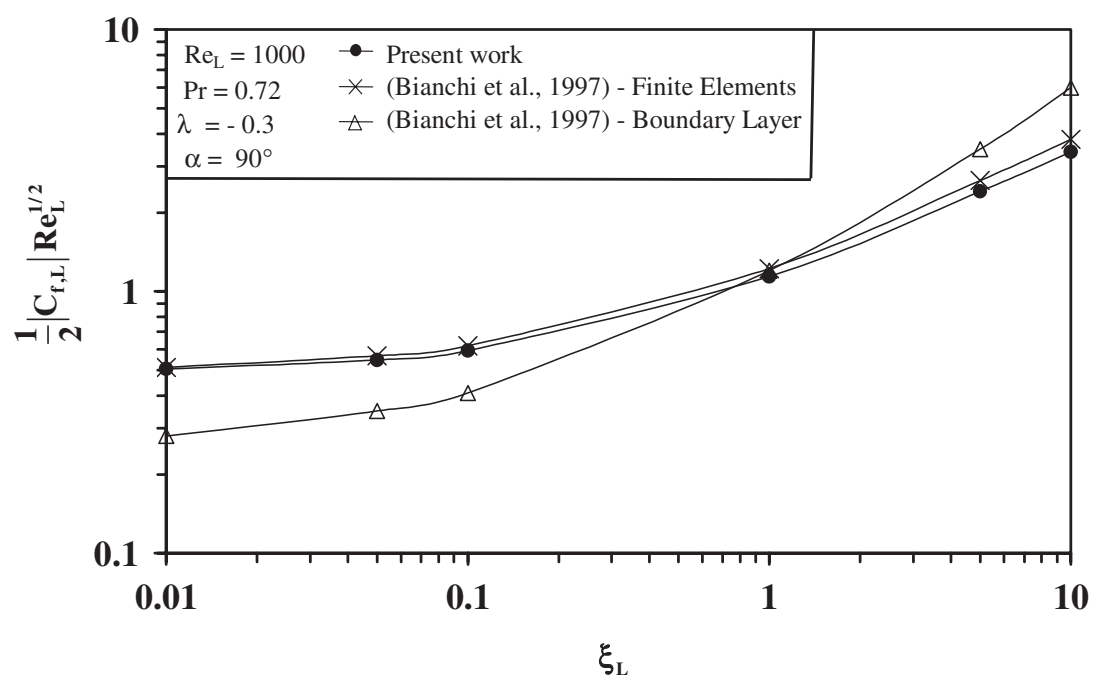

Fig. 3. Validation procedure of the local skin friction coefficient against literature results, for buoyancy-assisting flows. 


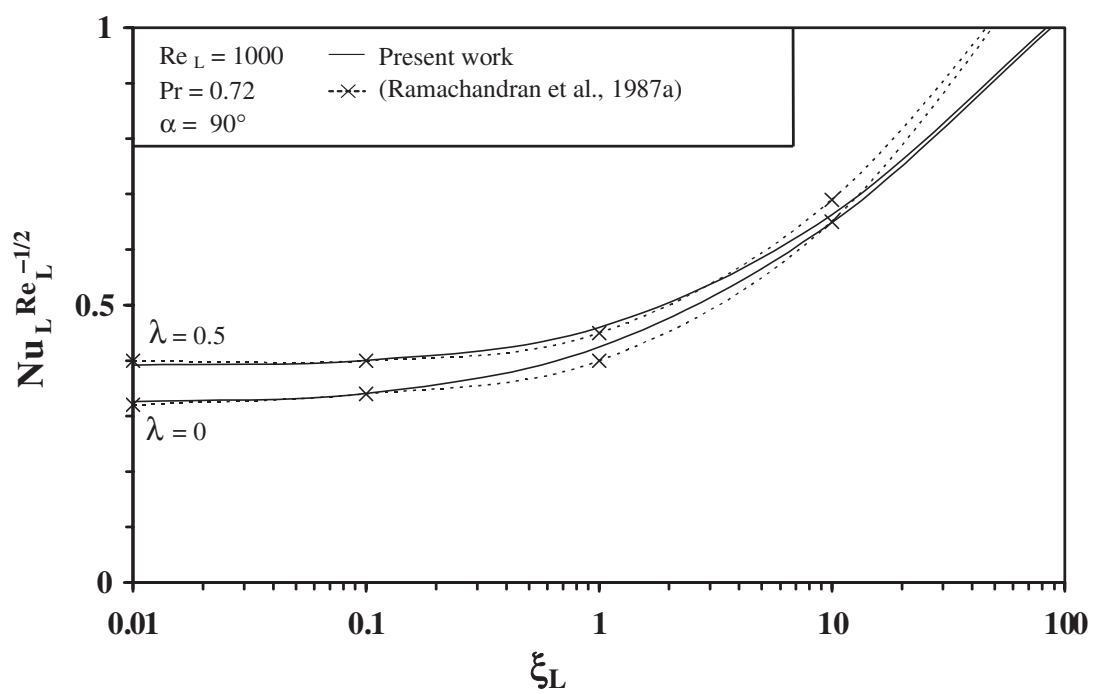

Fig. 4. Validation procedure of the local heat transfer coefficient against literature results, for buoyancy-assisting flows.

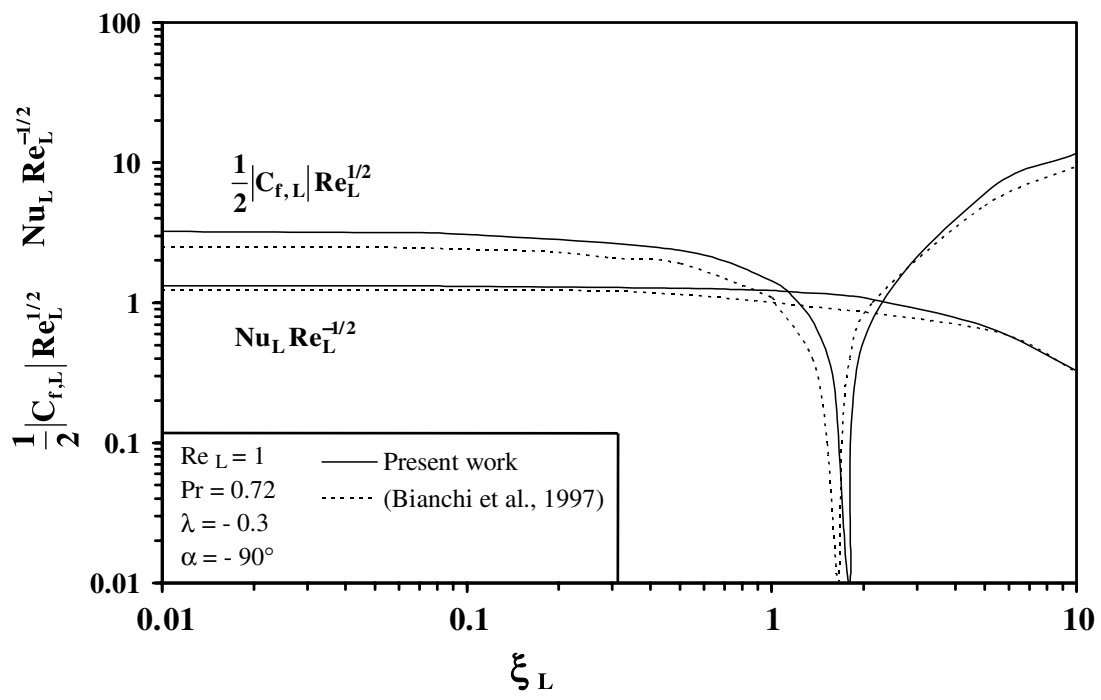

Fig. 5. Validation procedure of the local skin friction and heat transfer coefficients against literature results, for buoyancy-opposing flows.

the fact a semi-infinite plate is considered in the boundary layer formulation, whereas in the present model, according to Fig. 2, the plate has a finite length, $L$, therefore suffering the influence of downstream conditions where the plate no longer exists. Next, results for the opposing flow configuration are shown in Fig. 5, i.e., $\alpha=-90^{\circ}$. Bianchi et al. (1997) obtained results for opposing flow for vertical plates with a complete formulation, but only for low free stream velocities, i.e., $R e_{\mathrm{L}}=1$. Fig. 5 shows that the results are in very good qualitative and quantitative agreement, both for the fluid friction and heat transfer. Note that the velocity gradient at the wall decreases and reaches a zero value as $\xi_{\mathrm{L}}$ increases. At that point, there is no friction, since the fluid adjacent to the wall moves at the same velocity as the plate. Beyond that point, friction increases again, but $(\partial u / \partial y)$ becomes negative, so the friction factor, $C_{\mathrm{f}, \mathrm{L}}$, attains negative values, according to Eq. (14). Therefore, for clarity, Fig. 5 shows the absolute values of the friction factor. The same effect is expected to be present in all opposing flow configurations.

As it was discussed earlier in the text, Ramachandran et al. (1987a) presented results for flow and heat transfer from vertical and inclined moving sheets under the boundary layer assumptions for buoyancy-assisting flows, and by neglecting the streamwise pressure gradient in the formulation. The present treatment studies the flow configuration with inclined sheets according to Fig. 1 , with a complete formulation, therefore also considering the pressure gradient terms in the momentum equations and cases where the sheet moves either in the opposite or the same direction as the free stream. 
The presentation of the results for inclined sheets starts with the buoyancy-assisting cases. For a fixed moving sheet to free stream velocity ratio, $\lambda=0.3$, Fig. 6 shows the effect of the variation of the inclination angle, $\alpha$, and Reynolds number, $R e_{\mathrm{L}}$, on the wall averaged skin friction coefficient, $\bar{C}_{\mathrm{f}}$. The effect of $\alpha$ is negligible in the forced convection region of the graph, i.e., for the low $\xi_{\mathrm{L}}$ values, becoming important as $\xi_{\mathrm{L}}$ increases and buoyancy effects are present, then $\bar{C}_{\mathrm{f}}$ increases as $\alpha$ increases. An explanation lies in the fact that the value of the gravity component in the direction of the sheet decreases as $\alpha$ decreases. As expected, the forced convection scale, $\bar{C}_{\mathrm{f}} \sim R e_{\mathrm{L}}^{-1 / 2}$ is increasingly more appropriate for higher values of $R e_{\mathrm{L}}$, such that with low $\xi_{\mathrm{L}}$ values, for $R e_{\mathrm{L}} \geqslant 400$, the effect of the variation of $R e_{\mathrm{L}}$ is neglible on the group $\left(\frac{1}{2}\left|\bar{C}_{\mathrm{f}}\right| R e_{\mathrm{L}}^{1 / 2}\right)$. A similar behavior is observed with respect to the wall averaged Nusselt number, i.e., with the group $\left(\overline{N u} R e_{\mathrm{L}}^{-1 / 2}\right)$, as shown in Fig. 7. The effect of the inclination angle is more pronounced for higher $\xi_{\mathrm{L}}$ values, i.e., from the mixed to the natural convection region where $\overline{N u}$ increases as $\alpha$ increases, showing that a highest heat transfer rate occurs with the vertical wall configuration, i.e., when the gravity component in the direction

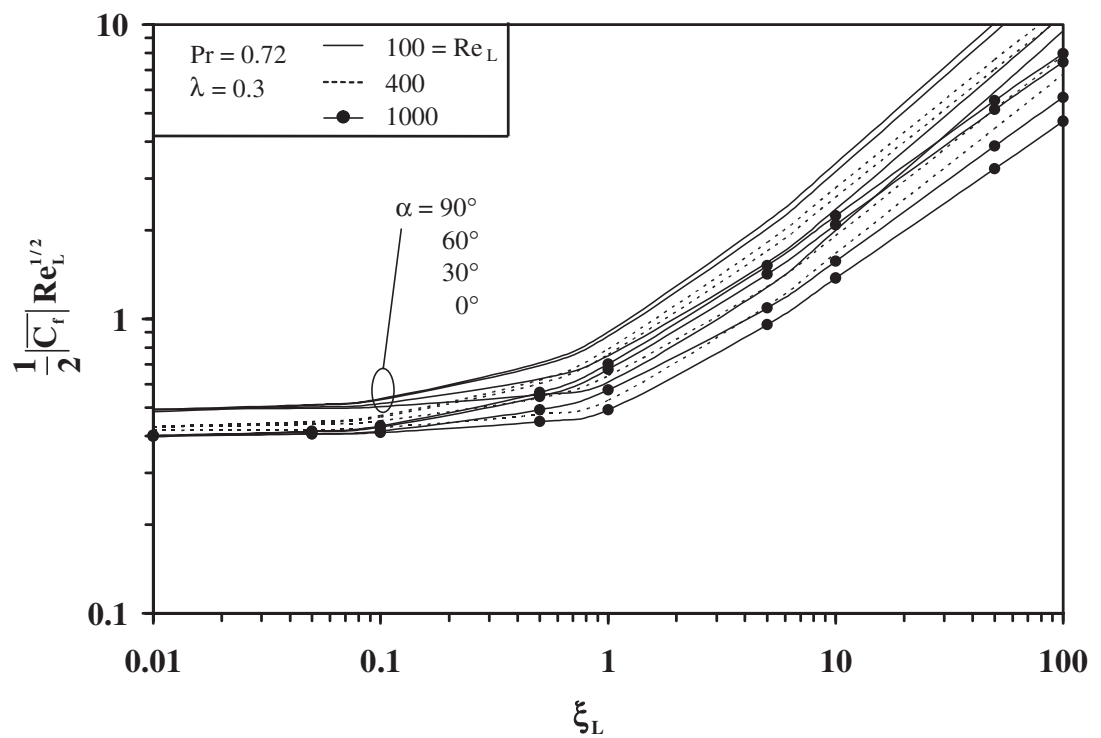

Fig. 6. The effect of the forced free stream flow, $R e_{\mathrm{L}}$, inclination angle and buoyancy on the wall averaged skin friction coefficient, for buoyancyassisting flows.

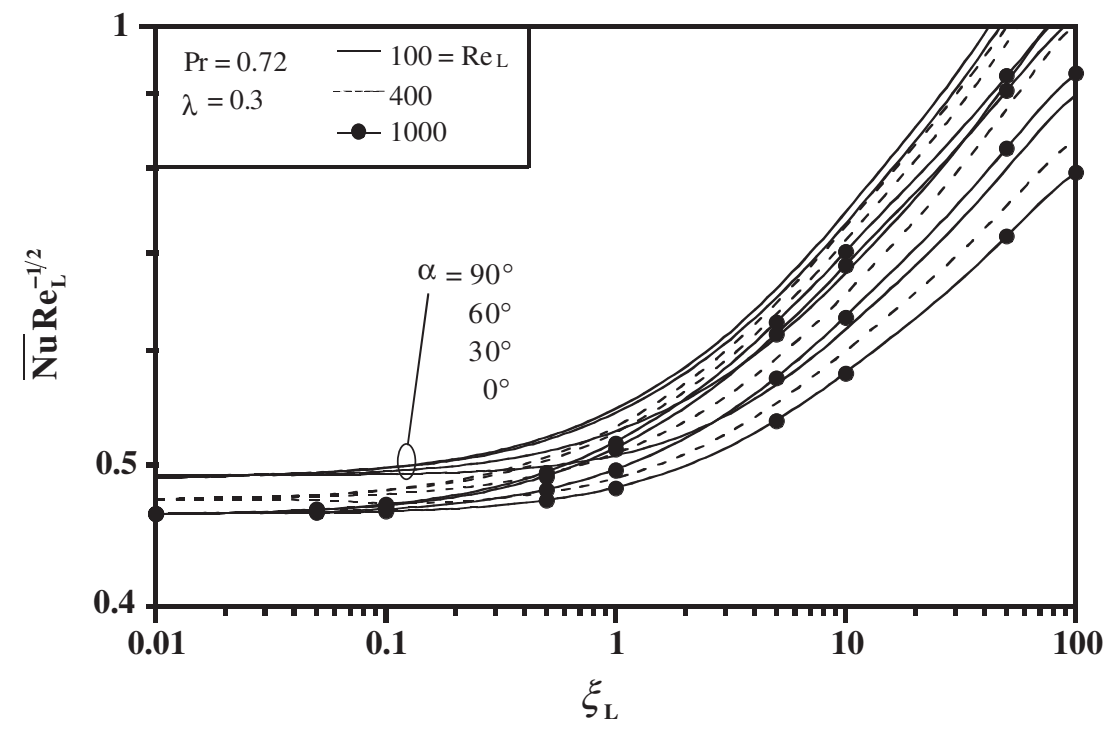

Fig. 7. The effect of the forced free stream flow, $R e_{\mathrm{L}}$, inclination angle and buoyancy on the wall averaged heat transfer coefficient, for buoyancyassisting flows. 
of the sheet is maximum. The forced convection scale, $\overline{N u} \sim R e_{\mathrm{L}}^{1 / 2}$ is increasingly more appropriate as $R e_{\mathrm{L}}$ increases, in the low $\xi_{\mathrm{L}}$ values region of the graph, i.e., the forced convection dominated region.

The effect of the variation of the moving sheet to free stream velocity ratio, $\lambda$, is investigated in Fig. 8, for $R e_{\mathrm{L}}=1000$. Friction is higher when the sheet moves in the opposite direction to that of the free stream. Departing from $\lambda=-0.3$, as the magnitude of $\lambda$ decreases and changes sign (i.e., moving in the same direction as the free stream), friction decreases, since the relative velocity between the sheet and the free stream is reduced. Again, the effect of the inclination angle is neg- ligible in the forced convection dominated regime and more pronounced from the mixed to pure natural convection region, with $\bar{C}_{\mathrm{f}}$ increasing as $\alpha$ increases, due to the same reasoning presented in the discussion of Figs. 6 and 7. The wall averaged Nusselt number dependence on $\lambda$ is shown in Fig. 9. In this case, $\overline{N u}$ is higher when the sheet moves in the same direction as the free stream. One possible explanation for this is the fact that the relative velocity between the sheet and the free stream is reduced as the magnitude of $\lambda$ decreases and changes sign, for negative values. The relative velocity between the sheet and the free stream continues to decrease as $\lambda$ changes sign, becomes positive and increases. Therefore

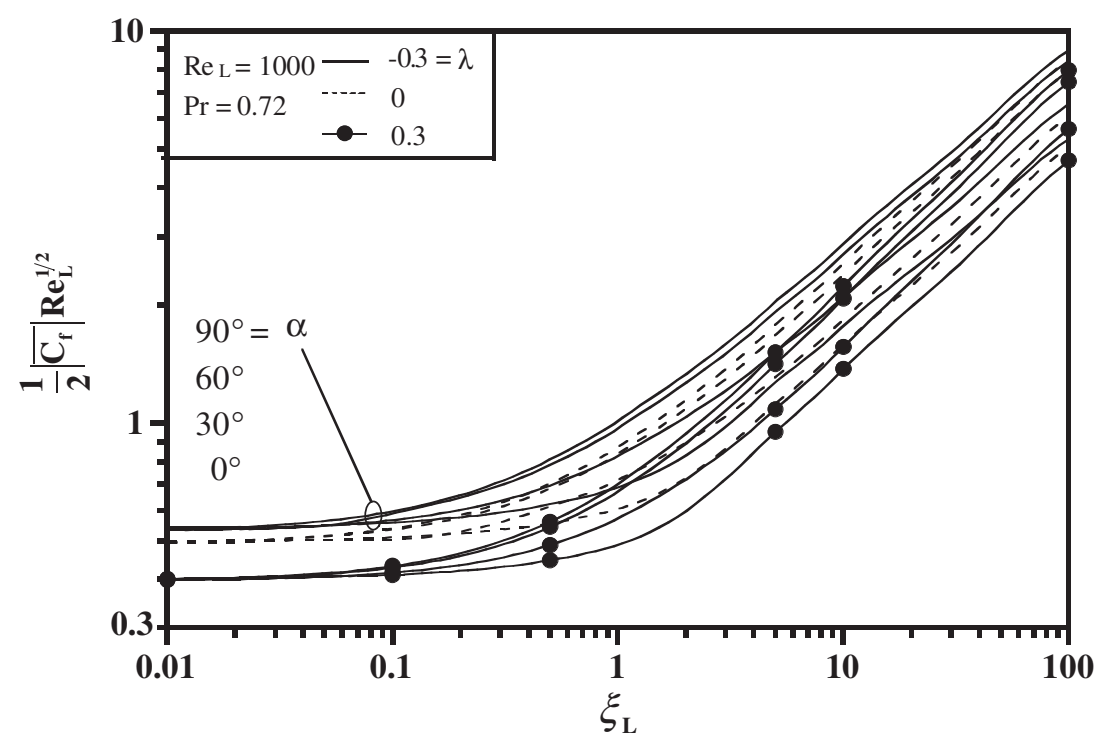

Fig. 8. The effect of the sheet velocity, $\lambda$, inclination angle and buoyancy on the wall averaged skin friction coefficient, for buoyancy-assisting flows.

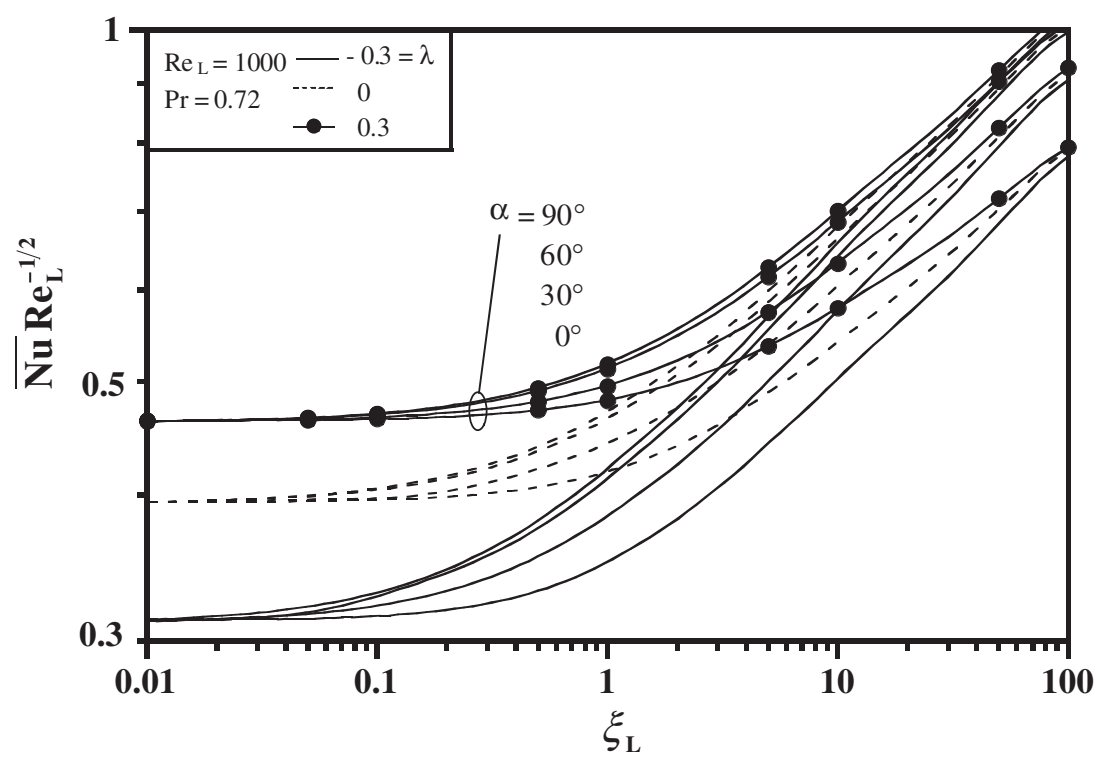

Fig. 9. The effect of the sheet velocity, $\lambda$, inclination angle and buoyancy on the wall averaged heat transfer coefficient, for buoyancy-assisting flows. 
a specific point on the sheet stays longer in thermal contact with the free stream as $\lambda$ varies from -0.3 to 0.3 , as shown in Fig. 9. The same trend is observed in the results shown in Fig. 4 for the vertical wall (and in the results obtained by Ramachandran et al., 1987a) for $\lambda \geqslant 0$, i.e., $\left(N u_{x} R e_{x}^{-1 / 2}\right)$ increases as $\lambda$ increases.

The numerical results for the buoyancy-assisting flows, with air $(\operatorname{Pr}=0.72), 100 \leqslant R e_{\mathrm{L}} \leqslant 1000,0^{\circ} \leqslant \alpha \leqslant$ $90^{\circ},-0.3 \leqslant \lambda \leqslant 0.3$ and $0 \leqslant \xi_{\mathrm{L}} \leqslant 100$ (i.e., from the forced, mixed to natural convection conditions) are correlated within $5 \%$ by an expression of the type recommended by Churchill (1977)

$$
\begin{aligned}
F=\{ & {\left[c_{0}+c_{1}(\lambda+0.3)+c_{2} \lambda(\lambda+0.3)\right]^{n} } \\
& \left.+b \cdot d \cdot a_{1}^{n} \xi_{\mathrm{L}}^{\left(a_{2} \cdot n \cdot e\right)}\right\}^{1 / n}
\end{aligned}
$$

where $F=F\left(R e_{\mathrm{L}}, \lambda, \alpha, \xi_{\mathrm{L}}\right)$ represents either the wall averaged skin friction group $\left(\frac{1}{2}\left|\bar{C}_{\mathrm{f}}\right| R e_{\mathrm{L}}^{1 / 2}\right)$ or the wall averaged Nusselt number group $\left(\overline{N u} R e_{\mathrm{L}}^{-1 / 2}\right)$, by utilizing the appropriate coefficients in Eq. (18).

For $F=\frac{1}{2}\left|\bar{C}_{\mathrm{f}}\right| R e_{\mathrm{L}}^{1 / 2}: \quad c_{0}=0.513+24.111 / R e_{\mathrm{L}} ; \quad c_{1}=$ $\left(f_{12}-c_{0}\right) / 0.3 \quad$ with $f_{12}=0.482+15.889 / R e_{\mathrm{L}} ; \quad c_{2}=$ $\left(f_{13}-2 f_{12}+c_{0}\right) / 0.18$ with $f_{13}=0.391+10.111 / R e_{\mathrm{L}}$; $n=(0.357 \alpha-0.175) \xi_{\mathrm{L}}+2 ; b=0.261 \alpha+0.599$ with $\alpha$ in radians; $a_{1}=-0.515 \lambda+0.829 ; a_{2}=0.09 \lambda+0.505$; $d=2.96 \times 10^{-7} R e_{\mathrm{L}}^{2}-7.48 \times 10^{-4} R e_{\mathrm{L}}+1.452, \quad$ and $e=2.03 \times 10^{-7} R e_{\mathrm{L}}^{2}-5 \times 10^{-4} R e_{\mathrm{L}}+1.3$.

For $F=\overline{N u} R e_{\mathrm{L}}^{-1 / 2}: \quad c_{0}=0.307+5.889 / R e_{\mathrm{L}} ; \quad c_{1}=$ $\left(f_{12}-c_{0}\right) / 0.3 \quad$ with $\quad f_{12}=0.391+3.778 / R e_{\mathrm{L}} ; \quad c_{2}=$ $\left(f_{13}-2 f_{12}+c_{0}\right) / 0.18$ with $f_{13}=0.46+3.222 / R e_{\mathrm{L}}$; $n=7.013 ; \quad b=0.547 \alpha+0.15$ with $\alpha$ in radians; $a_{1}=0.162 \lambda+0.469 ; \quad a_{2}=-0.07 \lambda+0.172 ; d=-7.4 \times$
$10^{-7} R e_{\mathrm{L}}^{2}+7.037 \times 10^{-4} R e_{\mathrm{L}}+1.037$, and $e=3.7 \times 10^{-7}$ $R e_{\mathrm{L}}^{2}-5.85 \times 10^{-4} R e_{\mathrm{L}}+1.215$.

All the numerical results were obtained with the dimensionless groups defined in Eqs. (6) and (7), which are based on adequate scales for the forced convection dominated regime, i.e., for low $\xi_{\mathrm{L}}$ values. Although convergence became increasingly difficult as $\xi_{\mathrm{L}}$ increased, in the buoyancy-assisting cases, it was possible to obtain results for $0 \leqslant \xi_{\mathrm{L}} \leqslant 100$ (i.e., from forced, mixed to natural convection conditions). However, in the buoyancy-opposing cases, where the forced convection flow opposes the natural convection flow, convergence was achieved only for $\xi_{\mathrm{L}}<1$. For this reason, the buoyancy-opposing converged results are presented and discussed, but no correlation is proposed since the entire $\xi_{\mathrm{L}}$-range has not been covered.

Figs. 10 and 11 show the flow and heat transfer results for the stationary plate, $\lambda=0$. The effect of the variation of the Reynolds number is investigated by direct comparison of the results of Fig. $10\left(R e_{\mathrm{L}}=400\right)$ with the results of Fig. $11\left(R e_{\mathrm{L}}=1000\right)$. The results are qualitatively similar, with slight quantitative differences, showing that the groups $\left(\frac{1}{2}\left|\bar{C}_{\mathrm{f}}\right| R e_{\mathrm{L}}^{1 / 2}\right)$ and $\left(\overline{N u} R e_{\mathrm{L}}^{-1 / 2}\right)$ are an appropriate scale for $R e_{\mathrm{L}} \geqslant 400$ in the low $\xi_{\mathrm{L}}$ values region of the graph, i.e., the forced convection dominated region. Numerical results are shown only up to the point where convergence was achieved. As expected, $\left(\frac{1}{2}\left|\bar{C}_{\mathrm{f}}\right| R e_{\mathrm{L}}^{1 / 2}\right)$ and $\left(\overline{N u} R e_{\mathrm{L}}^{-1 / 2}\right)$ decrease as $\xi_{\mathrm{L}}$ increases, since the buoyancy induced flow increases and opposes the forced flow. Both friction and heat transfer decrease from the limiting buoyancy-assisting horizontal plate $\left(\alpha=0^{\circ}\right)$ to the buoyancy-opposing vertical plate $\left(\alpha=-90^{\circ}\right)$ where the gravity component in the direction

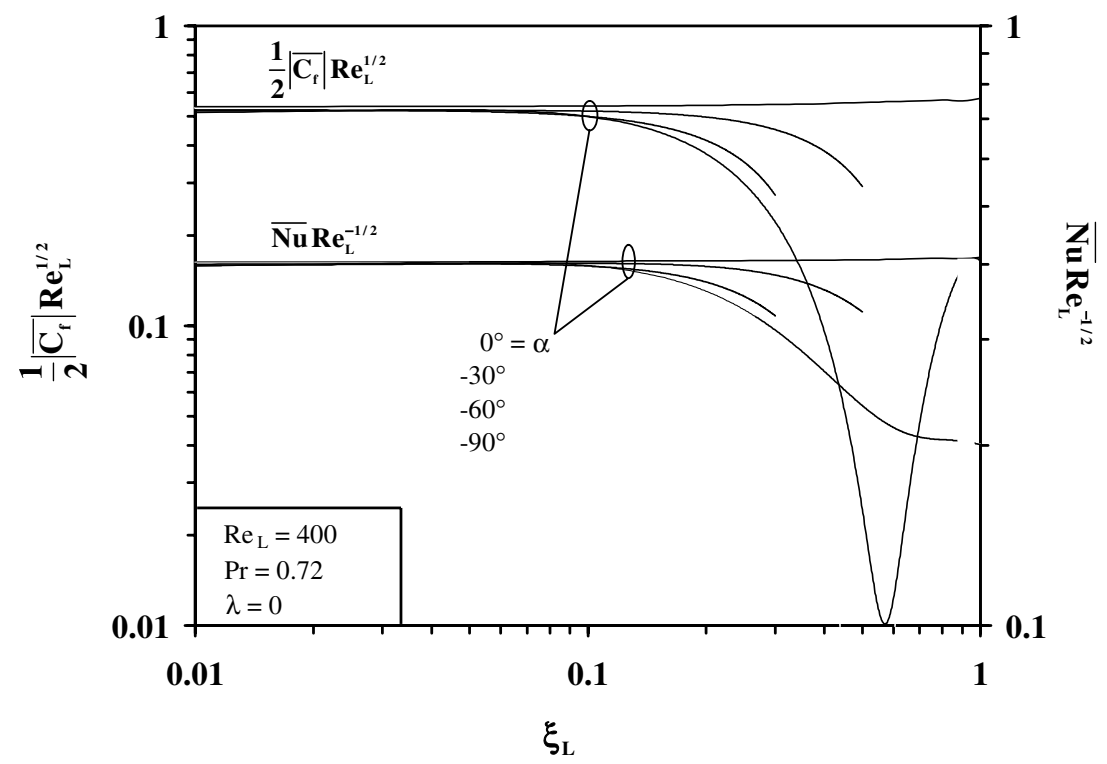

Fig. 10. The effect of the inclination angle and buoyancy on the wall averaged skin friction and heat transfer coefficients, for buoyancy-opposing flows on a stationary plate $\left(R e_{\mathrm{L}}=400\right)$. 


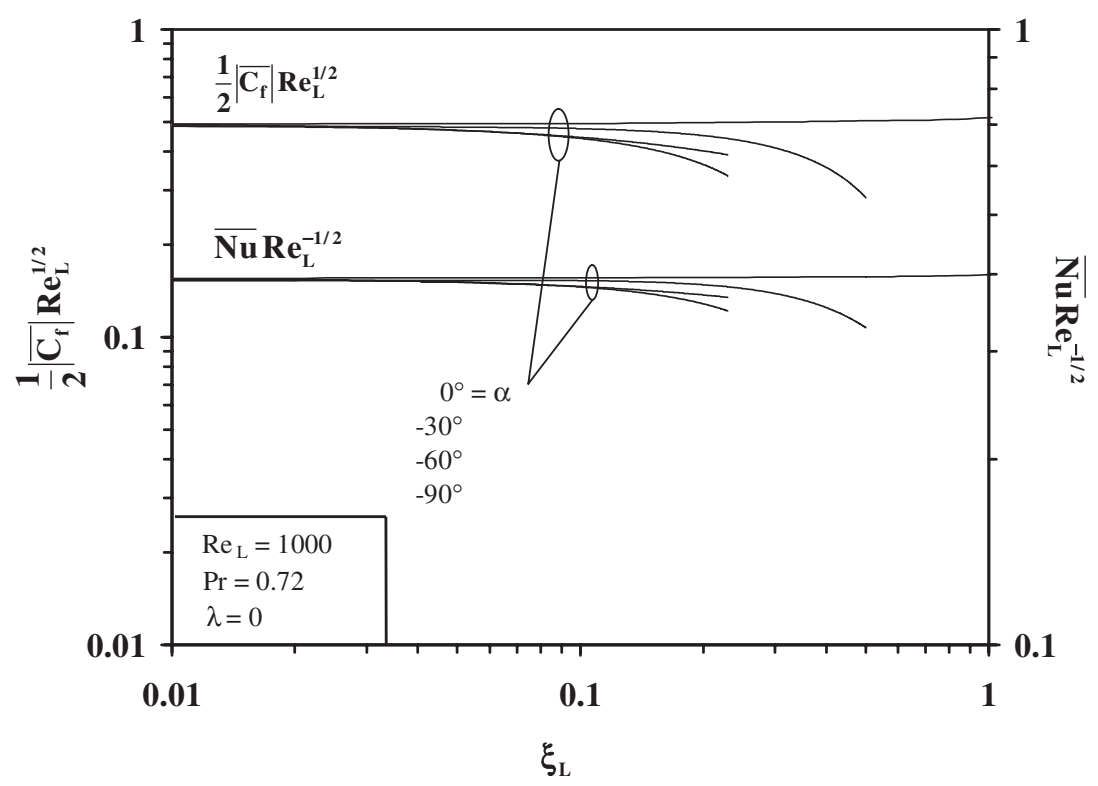

Fig. 11. The effect of the inclination angle and buoyancy on the wall averaged skin friction and heat transfer coefficients, for buoyancy-opposing flows on a stationary plate $\left(R e_{\mathrm{L}}=1000\right)$.

of the sheet is maximum, i.e., the buoyancy-opposing effect is maximum. In Fig. 10, for $R e_{\mathrm{L}}=400$, it was possible to reach a value of $\xi_{\mathrm{L}} \cong 0.57$ where the wall averaged friction factor becomes zero and changes sign, i.e., $(\partial u / \partial y)$ becomes negative, which is the same effect observed in Fig. 5, for the local friction factor. The same trend is observed in all other cases in Figs. 10 and 11. Close to that location, it is observed that $\left(\overline{N u} R e_{\mathrm{L}}^{-1 / 2}\right)$ reaches a minimum value which represents the minimum conduction heat transfer limit where there is no relative motion between the sheet and the fluid. From that value of $\xi_{\mathrm{L}}$ on, as the buoyancy induced flow increases, heat transfer is expected to increase again, but no convergence was achieved in this work beyond this point. All other cases show the same trend up to the point where convergence was achieved. Similar phenomena are observed in Figs. 12-15 which document the effect of the variation of the sheet velocity. In comparison with Figs. 10 and 11 , it is seen that when the sheet is moving in the direction opposite to the free stream $(\lambda=-0.3)$ the decreasing rate of $\left(\frac{1}{2}\left|\bar{C}_{\mathrm{f}}\right| R e_{\mathrm{L}}^{1 / 2}\right)$ and $\left(\overline{N u} R e_{\mathrm{L}}^{-1 / 2}\right)$ with respect to $\xi_{\mathrm{L}}$ is higher. Figs. 14 and $15(\lambda=0.3)$ show that the decreasing rate of $\left(\frac{1}{2}\left|\bar{C}_{\mathrm{f}}\right| R e_{\mathrm{L}}^{1 / 2}\right)$ and $\left(\overline{N u} R e_{\mathrm{L}}^{-1 / 2}\right)$ with respect to $\xi_{\mathrm{L}}$ is smaller than in the previous cases

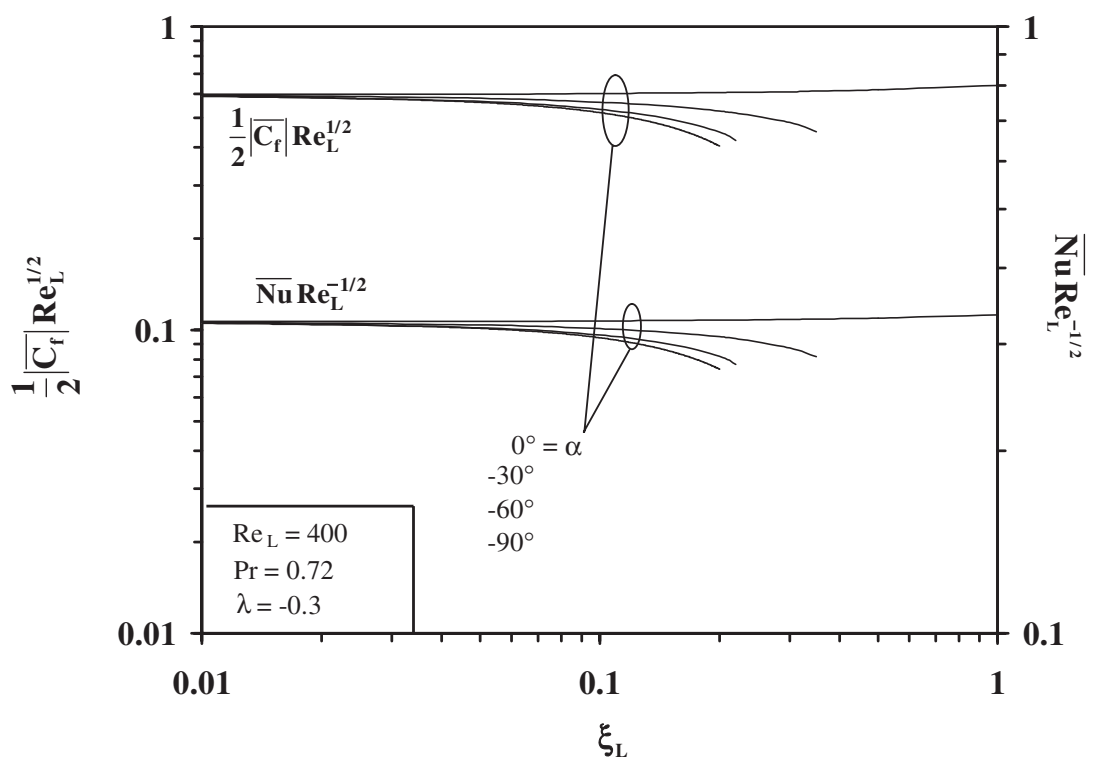

Fig. 12. The effect of the inclination angle and buoyancy on the wall averaged skin friction and heat transfer coefficients, for buoyancy-opposing flows on a plate moving in the opposite direction to the free stream $\left(R e_{\mathrm{L}}=400\right)$. 


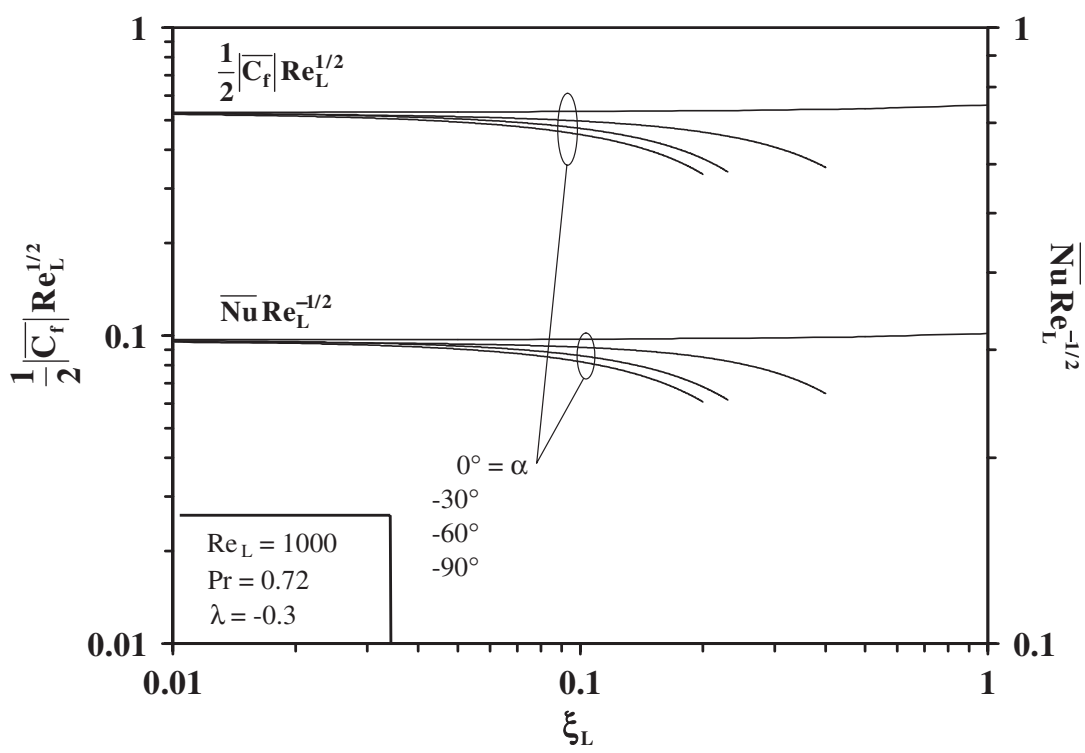

Fig. 13. The effect of the inclination angle and buoyancy on the wall averaged skin friction and heat transfer coefficients, for buoyancy-opposing flows on a plate moving in the opposite direction to the free stream $\left(R e_{\mathrm{L}}=1000\right)$.

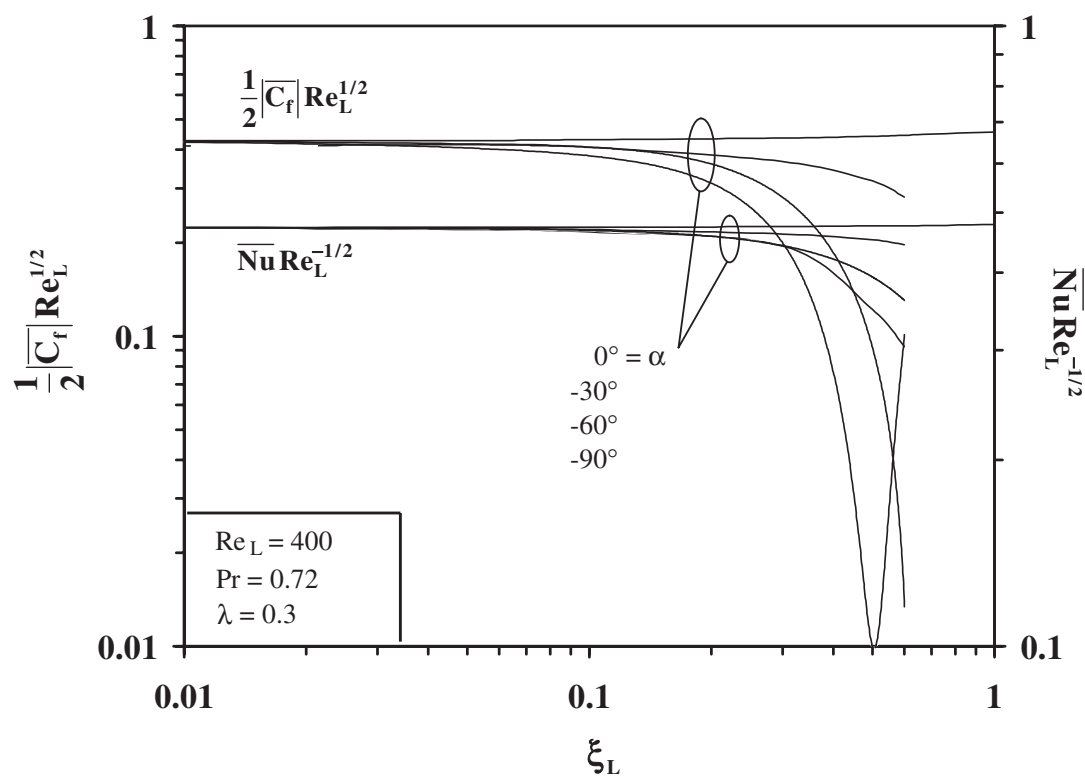

Fig. 14. The effect of the inclination angle and buoyancy on the wall averaged skin friction and heat transfer coefficients, for buoyancy-opposing flows on a plate moving in the same direction as the free stream $\left(R e_{\mathrm{L}}=400\right)$.

$(\lambda=-0.3$ and 0$)$. The conclusion is that the reduction in the wall averaged friction and heat transfer with respect to $\xi_{\mathrm{L}}$ is more accentuated as $\lambda$ decreases from positive to negative values.

\section{Conclusions}

In this study, an analysis has been carried out to predict convective transport occurring between air and a continuous inclined surface which moves with assisting or opposing flow with respect to the free stream, in the presence of gravity. Numerical solutions for fluid flow and heat transfer have been obtained for the set of (laminar regime) complete conservation equations using the finite element method. The accuracy of the numerical results was verified by direct comparison with results previously published in the literature for vertical surfaces with buoyancy-assisting flows. The review of the literature shows that heat and fluid flow solutions that cover all buoyancy-assisting and opposing flows for mixed convection on inclined surfaces are not available. 


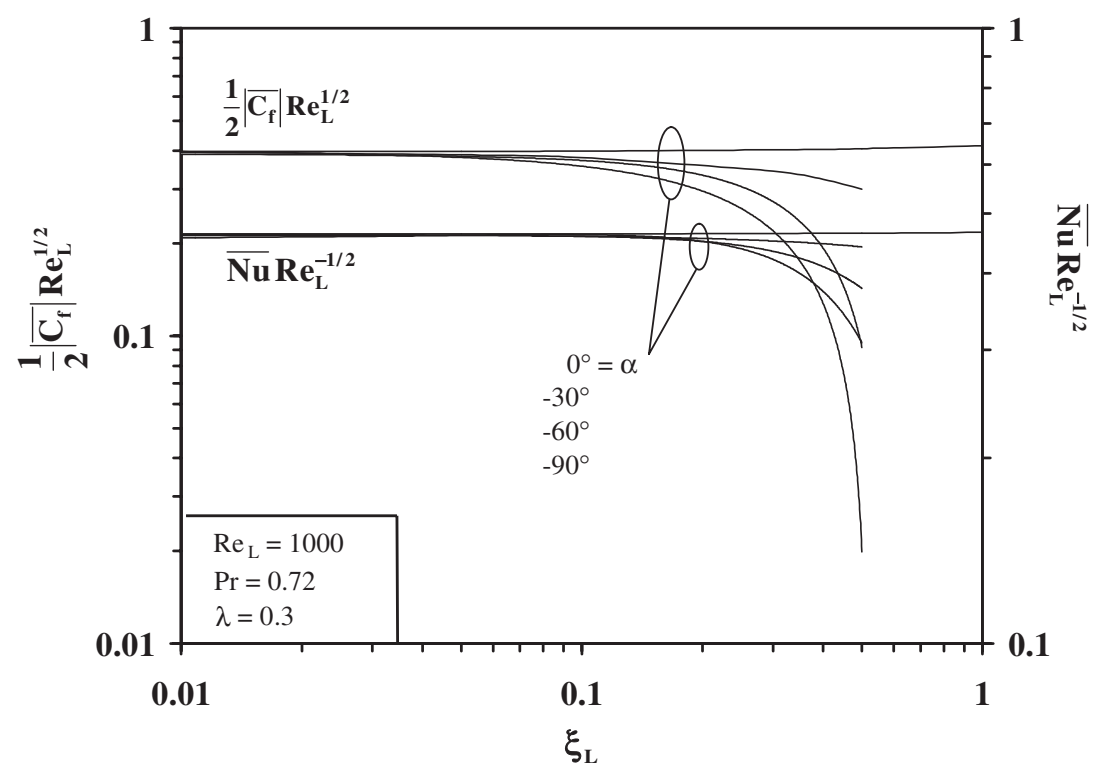

Fig. 15. The effect of the inclination angle and buoyancy on the wall averaged skin friction and heat transfer coefficients, for buoyancy-opposing flows on a plate moving in the same direction as the free stream $\left(R e_{\mathrm{L}}=1000\right)$.

Two objectives have been achieved with the present work: (i) fluid friction and heat transfer characteristics along inclined surfaces in laminar flow both for the buoyancy-assisting and opposing flows were predicted for several different process configurations, and (ii) the bulk of the numerical results was correlated in the form of analytical expressions valid for wide ranges of inclination angles and moving sheet relative velocities, for buoyancy-assisting flows.

The chief contribution of the work presented in this paper is that it focuses attention on the results of correlations for future scientific and industrial applications. The nondimensional results obtained for the wall averaged friction coefficient and Nusselt number could be applied extensively once the physical and operating parameters of the specific process under consideration are known. In order to establish more confidence in the numerical results, the model predictions should be validated experimentally at least for a few selected process configurations.

\section{References}

Abdelhafez, T.A., 1985. Skin friction and heat transfer on a continuous flat surface moving in a parallel free stream. International Journal of Heat and Mass Transfer 28, 1234-1237.

Ali, M.E., 1995. On thermal boundary layer on a power-law stretched surface with suction or injection. International Journal of Heat and Fluid Flow 16 (4), 280-290.

Ali, M., Al-Yousef, F., 1998. Laminar mixed convection from a continuously moving vertical surface with suction or injection boundary. Heat and Mass Transfer 33, 301-306.

Ali, M., Al-Yousef, F., 2002. Laminar mixed convection boundary layers induced by a linearly stretching permeable surface. International Journal of Heat and Mass Transfer 45, 4241-4250.
Al-Sanea, S.A., Ali, M.E., 2000. The effect of extrusion slit on the flow and heat-transfer characteristics from a continuously moving material with suction or injection. International Journal of Heat and Fluid Flow 21, 84-91.

Bianchi, M.V., Viskanta, R., 1993. Momentum and heat transfer on a continuous flat surface moving in a parallel counterflow free stream. Wärme-und Stoffübertragung 29, 89-94.

Bianchi, M.V.A., Branco, O.H.G., Vargas, J.V.C., Viskanta, R., 1997. Mixed convection heat transfer from a vertical plate in relative motion to a parallel air stream. In: 14th Brazilian Congress of Mechanical Engineering, XIV COBEM, 8-12 December 1977, Bauru, SP, Brazil.

Calkin, J.B., Parsons, J.L., 1957. Modern Pulp and Paper Making, third ed., Reinhold Publishing Coorporation, New York.

Chapiddi, P.R., Gunnerson, F.S., 1989. Analysis of heat and momentum transport along a moving surface. International Journal of Heat and Mass Transfer 32, 1383-1386.

Chen, C.H., 1999. Forced convection over a continuous sheet with suction or injection moving in a flowing fluid. Acta Mechanica 138, $1-11$.

Chen, C.H., 2000a. Heat transfer characteristics of a non-isothermal surface moving parallel to a free stream. Acta Mechanica 142, 195205.

Chen, C.H., 2000b. Mixed convection cooling of a heated, continuously stretching surface. Heat and Mass Transfer 36, 79-86.

Churchill, S.W., 1977. A comprehensive correlating equation for laminar, assisting, forced and free convection. AIChE Journal 23, $10-16$.

Erickson, L.E., Cha, L.C., Fan, L.T., 1966. The cooling of a moving continuous flat sheet. In: AIChE Chemical Engineering Progress Symposium Series, vol. 62, pp. 157-165.

Gampert, B., Abdelhafez, T.A., 1979. Navier-Stokes-Lösungen für das Strömungsfeld an einer kontinuierlich bewegten ebenen Platte. Zeitschrift für Angewandte Mathematik und Mechanik 59, T228$\mathrm{T} 231$.

Hussaini, M.Y., Lakin, W.D., 1987. On similarity solutions of a boundary layer problem with an upstream moving wall. SIAM Journal of Applied Mathematics 47, 669-709.

Jaluria, Y., 1992. Transport from continuously moving materials undergoing thermal processing. In: Tien, C.-L. (Ed.), Annual 
Review of Heat Transfer, vol. 4. Hemisphere, New York, pp. 187245.

Klemp, J.B., Acrivos, A., 1972. A method for integrating the boundary-layer equations through a region of reverse flow. Journal of Fluid Mechanics 53, 177-191.

Lindsay, J.D., 1992. New drying and dewaterng processses in papermaking. In: Tanasawa, I., Lior, N. (Eds.), Heat and Mass Transfer in Materials Processing. Hemisphere, New York, pp. 605622.

Minkoff, I., 1992. Material Processes: A Short Introduction. SpringerVerlag, Berlin.

Patankar, S.V., 1980. Numerical Heat Transfer and Fluid Flow. Hemisphere, New York.

Pop, I., Kumari, M., Nath, G., 1995. Free convection past a uniform flux surface inclined at a small angle to the horizontal. Fluid Dynamics Research 15, 57-67.

Ramachandran, N., Armaly, B.F., Chen, T.S., 1983. Mixed convection over a horizontal plate. ASME Journal of Heat Transfer 105, 420423.

Ramachandran, N., Chen, T.S., Armaly, B.F., 1987a. Mixed convection from vertical and inclined moving sheets in a parallel freestream. Journal of Thermophysics 1 (3), 274 281.

Ramachandran, N., Armaly, B.F., Chen, T.S., 1987b. Correlations for laminar mixed convection in boundary layers adjacent to inclined, continuous moving sheets. International Journal of Heat and Mass Transfer 30 (10), 2196-2199.

Reddy, J.N., Gartling, D.K., 1994. The Finite Element Method in Heat Transfer and Fluid Dynamics. CRC Press, Bocca Raton (Chapters 4-5).

Sakiadis, B.C., 1961a. Boundary-layer behavior on continuous solid surfaces: I. Boundary-layer equations for two-dimensional and axisymmetric flow. AIChE Journal 7, 26-28.

Sakiadis, B.C., 1961b. Boundary-layer behavior on continuous solid surfaces: II: The boundary-layer on a continuous flat surface. AIChE Journal 7, 221-225.

Sakiadis, B.C., 1961c. Boundary-layer behavior on continuous solid surface: III. The boundary-layer on a continuous cylindrical surface. AIChE Journal 7, 467-472.

Tsou, F.K., Sparrow, E.M., Goldstein, R.J., 1967. Flow and heat transfer in the boundary layer on a continuous moving surface. International Journal of Heat and Mass Transfer 10, 219-235.

Viskanta, R., 1992. Heat transfer from continuously moving materials: an overview of selected thermal processing problems. In: Cheng, J.S., Chung, S.H., Kim, K.H. (Eds.), The 6th International Symposium on Transport Phenomena in Thermal Engineering, vol. 1. The Korean Society of Mechanical Engineers, Seoul, Korea, pp. $1-10$.

Zienkiewicz, O.C., Taylor, R.L., 1989. In: The Finite Element Method, vol. 1. McGraw-Hill, London (Chapter 15). 